\title{
Políticas Públicas Educacionais: Desafios da Inclusão no Ensino Regular
}

\author{
Maria Zuleide de Lima Nogueiral
}

Resumo: A proposta deste artigo é mostrar diversas conceituações de políticas públicas e que as mesmas são diretrizes, princípios que direcionam a atuação do poder público. As políticas sociais públicas são aquelas que implantam operacionalização e manutenção dos serviços, programas, projetos e benefícios que são de inteira responsabilidade do Estado. $\mathrm{O}$ direito ao ensino regular possibilita às crianças o desenvolvimento de funções cognitivas e sociais. Estas aprendizagens envolvem tanto os professores, quanto os alunos. O objetivo geral deste artigo é: compreender as políticas educacionais, com ênfase nos desafios de inclusão no ensino regular, mostrando a importância do profissional da educação preparado. Os objetivos específicos foram: comparar a implantação destas políticas e aos avanços até os dias atuais; caracterizar a importância da educação para a sociedade; apontar os avanços, desafios e dificuldades para a inclusão da mesma no ensino regular; diferenciar programas, projetos e Leis implementadas. Tem-se um estudo descritivo, inserido na abordagem qualitativa. Isto é, realizado a partir $\mathrm{d}$ a leitura cuidadosa de recursos materiais como textos em consulta a internet, sites e livros bibliográficos, portanto sendo uma pesquisa bibliográfica e documental. Os dados obtidos fornecem um conteúdo onde destaca a importância dos avanços dentro das políticas públicas educacional, focando todo histórico e acontecimento durando cada governo. A educação é de suma importância para a conquista do desenvolvimento econômico de um país. Pois, os mais bem sucedidos em todas as áreas são aqueles que têm acesso à educação e consegue romper com as limitações.

Palavras chaves: Políticas Públicas; Desigualdades; Direito social; Educação e inclusão.

\section{Public Educational Policies: Challenges of Inclusion in Education}

\begin{abstract}
The purpose of this article is to show different concepts of public policy and that they are guidelines, principles that guide the actions of the government. Public social policies are those that implement operation and maintenance of services, programs, projects and benefits that are the responsibility of the State. The right to regular education enables children to develop cognitive and social functions. These learning involve both teachers as students. The aim of this article is: understand the educational policies, with emphasis on inclusion challenges in mainstream education, showing the importance of professional education prepared. The specific objectives were to compare the implementation of these policies and advances to the present day; characterize the importance of education in society; point out the advances, challenges and difficulties for inclusion in regular education; differentiating programs, projects and implemented laws. It is a descriptive study with a qualitative approach. This is done from $\mathrm{d}$ careful reading material resources such as texts on the internet consultation, websites and bibliographic books, therefore a bibliographical and documentary research. The data provide a content which highlights the importance of progress within the educational policies, focusing on every historical event and each lasting government. Education is of paramount importance to the achievement of economic development of a country. For the most successful in all areas are those who have access to education and can break away from the limitations.
\end{abstract}

Key words: Public Policy; Inequalities, social law; Education and inclusion.

${ }^{1}$ Maria Zuleide de Lima Nogueira. Mestranda em educação pela Anne SullivanUniversity.

E-mail: Zuleide.lima01@hotmail.com. 
Id on Line Revista Multidisciplinar e de Psicologia

Id on Line Multidisciplinary and Psycology Journal

\section{Introdução}

A Política Educacional pertence ao grupo de Políticas Públicas sociais do país. Este instrumento de implementação dos movimentos e referenciais educacionais se faz presente através da Legislação Educacional.

Para que se possa compreender melhor o significado dessa política, se faz necessário saber o que é Política Pública. Essa Política é de responsabilidade do Estado, com base em organismos políticos e entidades da sociedade civil, se estabelece um processo de tomada de decisões que derivam nas normatizações do país, ou seja, nossa Legislação. Por isto:

As Políticas Públicas envolvem todos os grupos de necessidades da sociedade civil, que são as Políticas Sociais, estas determinam o padrão de proteção social implementado pelo Estado, voltadas em princípio, à redistribuição dos benefícios sociais (INEP, 2006, p. 165), dentre eles o direito a educação. Para que este direito seja garantido com qualidade e de forma universal é implementada a Política Educacional.

No decorrer dos anos no Brasil, a Política Educacional fora definida de formas diferentes, por ser um elemento de normatização do Estado e que envolve interesses políticos diversos, no entanto, a Política Educacional de um país deve ser guiada pelo povo, respeitando o direito de cada indivíduo e assegurando o bem comum. Compreende-se, que de fato o exercício de construir uma Política, não se trata de um trabalho fácil de ser realizado, pois circunda uma nação, seus anseios, objetivos e valores.

Este tema é também de grande relevância para o educador pois mostra uma discussão na área da educação, compreendendo a construção desta política, desvelando a caracterização errônea dentro dela, e aponta também como profissional educador deve se preparar para o trabalho dentro da inclusão social.

Assim esta pesquisa tem o como objetivo geral; compreender as políticas educacionais, com ênfase nos desafios de inclusão no ensino regular, mostrando a importância do profissional da educação preparado. Tendo como objetivos específicos: comparar a implantação destas políticas e aos avanços até os dias atuais; caracterizar a importância da educação para a sociedade; apontar os avanços, desafios e dificuldades para a inclusão da mesma no ensino regular; diferenciar programas, projetos e Leis implementadas. 
Id on Line Revista Multidisciplinar e de Psicologia

Id on Line Multidisciplinary and Psycology Journal

Nele, está descrita uma breve trajetória das políticas públicas educacionais no Brasil, uma análise da educação brasileira. Principalmente, como fonte de implementação da educação nacional e das políticas que assim as definem é a Lei de Diretrizes e Bases da Educação Nacional (LDB), que no avanço dos anos foram reformuladas até o modelo atual datado de 1996 que sofreram alterações de acordo com os governos são as Leis de Diretrizes e bases da Educação Nacional (LDB).

Por ser um trabalho baseado em pesquisas se tem a necessidade de uma pesquisa bibliográfica nos materiais existentes, tantos nos textos disponibilizados em sala de aula, livros, como em sites na internet. Temos a memória alguns dos documentos que foram elementares a produção das Políticas Educacionais do nosso país, faz-se presente até os dias de hoje, diante da atual às dificuldades educacionais do Brasil, o manifesto dos pioneiros da Educação Nova de 1932, marco na definição de metas que são de prioridades e metas educacionais que necessitavam ser efetivadas.

O documento, como o próprio título faz referência, foi o pioneiro e notável instrumento de regulamentação da situação educacional brasileira, não funcionando apenas como um alerta a sociedade, mas também, como inspiração ao surgimento das Leis que regem a nossa educação.

É importante ressaltar que a exclusão social é marcada por uma série de fatores. Onde a educação é um dos maiores problemas de segregação social e ter políticas públicas que priorize a educação é vantagem não somente para o educando mais para o país como um todo, pois o alto índice de criminalidade está associado à baixa escolaridade, bem como o desemprego e seus efeitos. Por ser a educação essencial para a conquista do desenvolvimento sócio econômico de um país.

\section{Antecedentes históricos das Políticas Públicas Educacionais no Brasil}

A trajetória histórica das políticas educacionais no Brasil parece revelar uma nítida ligação com a forma conservadora e patrimonialista com a qual o Estado e a sociedade brasileira foram sendo forjados. Assim, em um cenário social cujas bases centravam-se em um modelo econômico agroexportador e na mão de obra escrava, a preocupação com o direito à educação veio aparecer tardiamente. Segundo Anísio Teixeira: 
Sem queremos nos estender muito ao passado, devemos recordar que, em todo o tempo da colônia, vivemos um tipo de governo de natureza absolutista, com a educação reduzida aos colégios confessionais, destinados dominantemente à formação do clero [...] (TEIXEIRA, 1967, p. 70).

Ainda segundo este educador (1976), o ensino brasileiro, com tendência ornamental e livresca, era destinado predominantemente para a camada mais abastada da sociedade.

Foi somente em fins do século XIX e início do século XX, no contexto da Primeira República quando o Estado brasileiro Oligárquico deslocava-se para uma "arrumação" Moderna/liberal, assumindo um modelo intervencionista que a educação começou a ser reclamada como necessária ao "desenvolvimento do país".

Nesse mesmo período, diversas vozes começaram a reclamar uma Política Educacional Nacional (AZEVEDO, 2006; ROMANELLE, 2005; SAVIANI, 2005).

Vozes que se aglomeraram dando vida a organizações colegiadas, tais como a Associação Brasileira de Educação, cujos marcos de luta se firmaram no Manifesto dos Pioneiros da Educação na década de 1930. Lançado em 1932, o Manifesto foi, sobretudo, um documento de política educativa no qual, para além da defesa da Escola Nova, estava a causa da luta maior pela escola pública laica, sendo esta responsabilidade do Estado. Resalto que as diretrizes desse manifesto influenciaram a Constituição de 1934 (Freitas, 2005; Saviani, 2005).

Segundo Teixeira (1967), a revolução de 1930 marca um período crítico em que começaram a florescer os primeiros sinais de inquietação, denunciadores do processo de integração política do país.

\footnotetext{
Nos fins da década de 20 e 30, parecia, assim, que estávamos preparados para a reconstrução de nossas escolas. A consciência dos erros se fazia cada vez mais palpitante e o ambiente de preparação revolucionária era propício à reorganização. O país iniciou a jornada de 30 com um verdadeiro programa de reforma educacional. Nas revoluções, como nas guerras, sabes-se, porém, como elas começam, mas não se sabe como acabam ( TEIXEIRA, 1976, 26)
}

Assim, podemos afirmar que a década de 1930 representou um salto no que se refere à regulamentação das políticas educacionais do país. Essa regulamentação foi impulsionada pela Reforma Francisco Campos, a qual instituiu o Ministério dos Negócios da Educação e Saúde 
Pública (SHIROMA, MORAIS, EVANGELISTA, 2002; SAVIANI, 2005). Uma série de decretos forma aos primeiros 'traços de bilro' dessa Reforma; como:

1) Decreto 19.850, de 11de abril de 1931, que criou o Conselho Nacional de Educação;

2) Decreto 19.851, de 11de abril de 1931, que dispôs sobre a organização do ensino superior no Brasil e adotou o regime universitário.

3) Decreto 19.852, de 11de abril de 1931, que dispôs sobre a organização da Universidade do Rio de janeiro.

4) Decreto 19.890, de 18 de abril de 1931, que dispôs sobre a organização do ensino secundário.

5) Decreto 19.941, de 30 de abril de 1931, que instituiu o ensino religioso como matéria facultativa nas escolas públicas do país.

6) Decreto 20.158, de 30 de junho de 1931, que organizou o ensino comercial e regulamentou a profissão de contador.

7) Decreto 21.241, de 14 de abril de 1932, que consolidou as disposições sobre a organização do ensino secundário.

A partir de 1937, com o Estado Novo, imposto pelo Presidente Getúlio Vargas, bem com o fechamento do Congresso Nacional, a constituição de 1934 foi revogada e em seu lugar impôs-se ao país uma nova Constituição tal esta ficaria conhecida como "Polaca", por ter sido inspirada na Constituição da Polônia.

Foi durante este período autoritário que aconteceu uma segunda Reforma do ensino no Brasil, agindo como uma espécie de "estabilizador" das forças mais conservadoras da época. Criaram-se as famosas "Leis Orgânicas do Ensino", as quais acabaram por ampliar e flexibilizar a reforma educacional anterior (SHIROMA, MORAIS, EVANGELISTA, 2002). Assim,

Todo o movimento era pela reforma de métodos, e pela implantação de novos tipos de educação. Surgiu a universidade. Ensaiou-se o ensino médio flexível, com a integração do ensino geral com o técnico no Distrito Federal. A escola primaria recuperou o prestigio e deu-se inicio à reforma dos seus objetivos e processos de ensino. A vinda de professores estrangeiros para as novas escolas superiores, em São Paulo e no Rio de Janeiro era uma coisa vantajosa e promissora. [...]. (TEIXEIRA, 1976, p.26)

Em fins da década de 1940, um fervoroso debate em torno da construção da Lei de Diretrizes e Bases da Educação - LDB, Lei 4.024, começava a ganhar forma. Para tal tarefa, o 
Id on Line Revista Multidisciplinar e de Psicologia

Id on Line Multidisciplinary and Psycology Journal

então ministro Clemente Mariano nomeou uma comissão de especialistas presidida por Lourenço Filho, que após estudos encaminhou uma proposta ao Congresso Nacional.

Esse longo e intenso debate foi acompanhado por uma guerra ideológica que chegou a durar cerca de 13 anos. De um lado, as fortes pressões conservadoras e privatistas; de outro, o Movimento em Defesa da Escola Pública, os Movimentos de Cultura Popular, o Movimento de Educação de Base, o Novo Manifesto. Conforme podemos perceber, nas palavras de Teixeira, havia expectativas e aspirações positivas em relação a esta Lei, ou seja, indicativos de que esta traria profundas mudanças para a estrutura da educação brasileira:

Apesar dos embates, das expectativas positivas e da força dos movimentos progressistas, a aprovação da LDB de 1961 causou prejuízos para educação, especialmente no que se refere à sua ampliação, pois fortaleceu o setor privado e limitou a expansão do ensino público. Fazenda (1984) relata que com base nesta Lei a questão da obrigatoriedade escolar do ensino primário foi oficialmente anulada pelo artigo 30. Sob a égide da referida Lei, a estrutura do ensino no Brasil ganhou a seguinte forma:

a) Ensino Primário de cinco anos;

b) Ensino Médio dividido em: Ciclo ginasial com quatro anos e Ciclo Colegial com três anos (científico, clássico, técnico ou normal).

Ainda com base na Lei $n^{\circ}$ 4.024/61 das Diretrizes e Bases da Educação Nacional, foi elaborado em 1962, pelo Conselho Nacional de Educação, o primeiro Plano Nacional de Educação, que estabelecia objetivos e metas qualitativas e quantitativas para a educação em um período de oito anos (Cury, 2006).

Acrescentando aqui o processo de criação dos diversos organismos internacionais, tais como: Fundo Monetário Internacional - FMI, Organização das Nações Unidas - ONU, Banco Internacional para a Reconstrução e o Desenvolvimento - BIRD etc. (Bruno, 1997). Tal processo de criação aconteceu em um período que se estendeu até o pós-guerra. Esses organismos passaram a interferir no Brasil, de forma mais precisa, a partir do Golpe Militar.

Sobre o mesmo assunto em 1964, aconteceu o Golpe Militar no Brasil, instaurando um regime autoritário e antidemocrático, o qual se prolongou até 1985. Sua instalação acabou por abafar todos os obstáculos que, no âmbito da sociedade civil, pudessem perturbar o processo de adaptação econômica e política que se impunha ao país (SHIROMA, MORAIS, EVANGELISTA, 2002). 
Id on Line Revista Multidisciplinar e de Psicologia

Id on Line Multidisciplinary and Psycology Journal

No campo educacional, as reformas do ensino empreendidas pelo Regime Militar, apesar de absorverem alguns elementos do debate anterior, guardavam sinuosos processos de recondução.

$\mathrm{Na}$ prática, implantou-se um pacote de leis, decretos-leis e pareceres relativos à educação objetivando garantir um desenho de política educacional orgânica, nacional e abrangente. Citaremos alguns dos dispositivos criados nessa nova configuração para exemplificar:

1) Lei 4.464, de 9 de novembro de 1964, que regulamentou a participação estudantil.

2) Lei 4.440, de 27 de outubro de 1964, que institucionalizou o salário-educação.

3) Decreto 57.634, de 14 de janeiro de 1966, que suspendeu as atividades da UNE.

4) Lei 5.540 , de 28 de novembro de 1968, que fixou as normas de organização e funcionamento do ensino superior.

5) Lei 5.692, de 11 de agosto de 1971, que fixou as diretrizes e bases para o ensino de $1^{\circ}$ e $2^{\circ}$ graus.

A Lei 5.692 introduziu mudanças profundas na estrutura do ensino vigente até então, tais como: ampliação da obrigatoriedade escolar para oito anos; instituição da obrigatoriedade da faixa etária de 7 aos 14 anos; profissionalização automática no segundo grau; extinção do exame de admissão no ginásio, dentre outras modificações. Com base nessa lei, a estrutura do ensino no Brasil ganhou novo desenho:

a) $1^{\circ}$ grau constituído por oito séries.

b) $2^{\circ}$ grau constituído por três séries (habilitações plenas ou parciais)

Apesar da aparente "inovação" no discurso, o Regime Militar deixou fortes resquícios não satisfatórios, pois nessa época foram diminuídos drasticamente os recursos para a educação. Assim, chegou-se à década de 1980 com os seguintes índices: 50\% das crianças repetiam ou eram excluídas ao longo da $1^{\text {a }}$ série do primeiro grau; $30 \%$ da população eram constituídos de analfabetos; $23 \%$ dos professores eram leigos; e 30\% das crianças estavam fora da escola (Shiroma, Morais, Evangelista, 2002).

Nesse contexto, em fins da década de 1970, em que as pressões contra o Regime Militar se intensificaram, surgiram diversas associações científicas e sindicais da área, tais como: a Associação Nacional de Pesquisa e Pós-graduação em Educação (ANPED), a Associação 
Id on Line Revista Multidisciplinar e de Psicologia

Id on Line Multidisciplinary and Psycology Journal

Nacional de Docentes do Ensino Superior (ANDES), a Confederação Nacional de Trabalhadores da Educação (CNTE), dentre outras.

E assim, como "conta" a história, os anos de 1980 foram se abrindo, representando uma ruptura com o pensamento educacional vigente na década anterior. A luta dos educadores a partir desse momento, no contexto de um movimento mais geral pela democratização da sociedade, gerou importantes contribuições para a educação como um todo (Freitas, 2002). Em síntese, a luta destas entidades assumiu as seguintes direções:

a) Melhoria da qualidade na educação,

b) Valorização e qualificação dos profissionais da educação,

c) Democratização da gestão,

d) Financiamentos,

e) Ampliação da escolaridade obrigatória abrangendo creche, pré-escola, primeiro e segundo graus.

Assim, com término do Regime Militar, eleição indireta de Tancredo Neves para presidente em 1985 e a vitória dos partidos de oposição nos anos 1980 em eleições estaduais e municipais, abriram-se as possibilidades da presença, na administração, de alguns intelectuais oriundos das universidades. Desta forma, aos poucos, os governos locais começaram a projetar uma política educacional contraria à da ditadura militar e com maior sintonia de acordo com anseios dos educadores.

A Carta Magna traz no corpus do seu texto muito das reivindicações dos educadores, respeitando o consenso da área, versando sobre temas como: gestão democrática, financiamento da educação e valorização profissional. Entretanto, as novas configurações internacionais acabam por 'abafar' um pouco destas conquistas (CAIADO, 2008).

Ainda neste cenário, as discussões sobre a LDB começam a se intensificar, adentrando a década de 1990. Contudo, o que se materializou sob a forma de "consenso", foi um habilidoso jogo linguístico que invertia termos e sinais, de modo a torná-los condizentes com os novos paradigmas que referenciavam a mudança almejada para a educação no país (SHIROMA, MORAIS, EVANGELISTA, 2002). 
Id on Line Revista Multidisciplinar e de Psicologia

Id on Line Multidisciplinary and Psycology Journal

\section{Políticas Educacionais na Década de 1990}

Na década de 1990 foram abertas com expectativas positivas em relação ao "delinear" das políticas educacionais. Expectativas essas que, ao longo do processo, foram se desfazendo devido às mudanças instauradas tanto na curta gestão de Fernando Collor de Mello e Itamar franco quanto na gestão de Fernando Henrique Cardoso na presidência do país, bem como aos rumos que foi assumindo o processo de elaboração e condução da Lei de Diretrizes e Base da Educação de 1996.

Em relação à continuidade da discussão da LDB, em síntese é possível salientar que o projeto aprovado em 1996 não correspondia aos anseios da década anterior. Vejamos: a história nos mostra que tivemos dois projetos de LDB: um delineado por Demerval Saviani, no qual as reivindicações da área educacional foram incorporadas em sua totalidade, e outro Projeto apresentado pelo Senador Darcy Ribeiro (PDT-RJ), que não contemplava as essas reivindicações.

Com a chegada de Fernando Henrique Cardoso à presidência, em 1994, iniciou-se uma nova composição do governo, e nela, Paulo Renato Souza assumiu o Ministério da Educação. A partir dessa nova organização de governo, o projeto delineado pelo Senador Darcy Ribeiro, sob a defesa de José Jorge (PFL-PE), foi sancionado sem qualquer veto (SHIROMA, MORAIS, EVANGELISTA, 2002; SAVIANI, 2008).

O ensino no Brasil ganhou uma nova estrutura em que o ensino brasileiro com base naquela nova LDB e segundo a lei, a Educação básica abrange: a) Educação infantil constituída pela creche para crianças de zero a três anos e pré-escolas para crianças de quatro a seis anos; b) Ensino fundamental constituído por oito anos; c) Ensino médio constituído por três séries. Com o projeto de Darcy Ribeiro, o governo acabou ceifando parte da fecundidade debatidas no movimento dos educadores, iniciados na década de 1980.

Várias bandeiras que foram levantadas durante o movimento acabaram distorcidas ou completamente descaracterizadas de sua ideia original, como por exemplo: capacitação de professores foi traduzida em profissionalização; participação da sociedade civil assumiu a forma de articulação com empresários e ONGs; descentralização significou desobrigação do Estado; autonomia ganhou contorno de liberdade para captação de recurso; melhoria da 
qualidade da educação traduziu-se em adequação ao mercado, sendo que o aluno transformouse em consumidor (SHIROMA, MORAIS, EVANGELISTA, 2002).

Tudo isto foi necessária ao governo de Fernando Henrique, pois naquele contexto, agências financiadoras internacionais (FMI, Banco Mundial etc.), solicitavam aos países em desenvolvimento que reduzissem gastos públicos, privatizassem suas empresas públicas e, nas atividades custeadas pelo estado, encontrassem novas formas de recurso (GRACINDO E KENSKI, 2001).

Desta forma,

Foi no governo de Fernando Henrique Cardoso, no ano de 1995, que entrou em curso a Reforma do Estado, articulada pelo Ministério da Administração e Reforma do Estado (MARE) e tendo como elemento disparador a publicação do documento "Plano Diretor da Reforma dos Aparelhos do Estado". A justificativa para tal reforma foi a de "[...] melhorar o desempenho da máquina governamental para, ao final, proporcionar serviços melhores para o benefício do cidadão" (GANDINI; RISCAL, 2008, p. 41).

Foi assim que a LDB de 1996, Lei no 9.394/96, sinalizou claramente para mudanças nas responsabilidades dos entes federados quanto à manutenção e ao desenvolvimento do ensino em seus diferentes níveis. O teor da citada lei induz fortemente à descentralização da educação, direcionando os seus gastos por intermédio da criação do Fundo de Manutenção e Desenvolvimento do Ensino Fundamental e da Valorização do Magistério - FUNDEF (Oliveira, 2008).

Ainda durante o governo de FHC, não podemos deixar de citar o Plano Nacional de Educação, regulamentado pela Lei 10.172 de 09 de janeiro de 2002, o qual dava corpo e assegurava a continuidade das mudanças em curso. Em síntese, podemos dizer que tal Plano teve como grande equívoco a ênfase ao Ensino Fundamental acima dos outros níveis de ensino (Hermida, 2006).

\section{O Governo pós Década de 1990: Presidente Lula}

O governo do presidente Luiz Inácio Lula da Silva, que teve início no ano de 2003, nasceu rodeado pelas expectativas de mudanças em toda a sociedade. Nesse governo, a princípio, entraram em curso programas de caráter compensatório denotando, em parte, serem 
Id on Line Revista Multidisciplinar e de Psicologia

Id on Line Multidisciplinary and Psycology Journal

orientados pela mesma lógica de seu antecessor. Com a entrada de Tarso Genro, que tinha como secretário executivo o atual ministro Fernando Haddad, as ações começaram a ser reconduzidas sendo possível, nessa gestão, a implantação de políticas tanto de médio quanto de longo prazo, em um movimento que sinalizava algumas rupturas (Oliveira, 2009; Pinto, 2009).

Destacam-se algumas das medidas implantadas:

O Programa Universidade para Todos; 2) O Programa de Apoio a Planos de Reestruturação e Expansão das Universidades Federais (REUNI; 3) A instituição do Fundo de Manutenção e Desenvolvimento da Educação Básica e de Valorização do Magistério FUNDEB; 4) O Plano de Desenvolvimento da Educação - PDE.

A última ação, programa e política citada merece maior atenção pela sua complexidade. Vejamos: o Plano de Desenvolvimento da Educação (PDE), apresentado pelo Ministério da Educação em abril de 2007, constitui-se em um conjunto de 52 ações; algumas delas foram incorporadas e outras foram sendo criadas. Tais ações encontram-se organizadas em quatro eixos, quais sejam: Educação Básica, Educação Superior, Educação Profissional e Tecnológica, Alfabetização e Educação Continuada.

Dentro desses eixos, as seguintes ações foram ora anexadas, ora criadas: FUNDEB, Pró-infância, Ensino Fundamental de nove anos, Provinha Brasil, Programas de apoio ao Ensino Médio, Luz para todos, Educa censo, Prova Brasil, PDE-Escola, Olimpíadas Brasileiras de Matemática das escolas públicas, Olimpíadas Brasileiras da Língua Portuguesa escrevendo o futuro, Mais Educação, Caminho da Escola, PNATE, Pró-escola, Proinfo, Biblioteca na Escola, Saúde na escola, Olhar Brasil, Educação Especial, Brasil alfabetizado, PNLA, Proeja, Projovem campo, Brasil profissionalizado, IFET, E-TEC Brasil, Catálogo Nacional dos Cursos Técnicos, Catálogo dos Cursos Superiores de Tecnologia, Piso Salarial do magistério, Sistema Nacional de Formação de Professores, Pripid, UAB, Pró-letramento, Pró-funcionário, Expansão do Ensino Superior, dentre outros.

A partir da adesão ao Plano de Metas Compromisso Todos pela Educação, os estados e municípios elaboram seus respectivos Planos de Ações Articuladas - PAR. Para auxiliar na elaboração do PAR, o Ministério da Educação passou a oferecer o sistema chamado de SIMEC - Módulo PAR Plano de Metas -, integrado aos sistemas que já possuía, e que pode ser acessado de qualquer computador conectado à internet, representando uma importante evolução 
Id on Line Revista Multidisciplinar e de Psicologia

Id on Line Multidisciplinary and Psycology Journal

tecnológica, com agilidade e transparência nos processos de elaboração, análise e apresentação de resultados dos PAR.

Como instrumento de referência de identificação dos municípios, o MEC conta com o Índice de Desenvolvimento da Educação Básica - IDEB, o qual é um indicador calculado com base nos dados de rendimento do fluxo escolar e do desempenho dos alunos nos exames nacionais.

O tensionamento relativo ao programa e política PDE tem sido destacado por Saviani (2007). Nesta produção, o autor questiona em que medida esse programa (PDE) se revela efetivamente capaz de enfrentar a questão da qualidade do ensino das escolas de educação básica. Destaca Saviani (2007) que o PDE foi saudado como um plano que, finalmente, estaria disposto a enfrentar esse desafio, focando prioritariamente os níveis de qualidade do ensino ministrado em todas as escolas de educação básica do país. Adverte este autor acerca da demasiada ambição do "Plano", agregando ações que incidem sobre os mais variados aspectos da educação em seus diversos níveis e modalidades.

\section{Educação, Direito Social e Igualdade para Todos}

O contexto social é marcado pela necessidade de adquirir conhecimentos e cada vez mais o saber é requisito para anular as desigualdades reinantes em todo o mundo, porém não basta somente estudar em "excelentes escolas”, é necessário ter um aprendizado.

A exclusão social é marcada por uma série de fatores e que a educação é um dos maiores problemas de segregação social e ter políticas públicas que priorize a educação é vantagem não somente para o educando mais para o país como um todo, pois o alto índice de criminalidade está associado a baixa escolaridade, bem como o desemprego e seus efeitos. A educação é essencial para a conquista do desenvolvimento sócio econômico de um país. É por este motivo que os países desenvolvidos possuem altos índices de escolarização. Podemos afirmar que a educação está entre as atitudes mais importantes de uma sociedade. Porém, a nível nacional, nos encontramos diante de um quadro histórico educacional extremamente diversificado. Uma grande porcentagem da população brasileira ainda é privada da educação escolar, sem acesso a 
informações elementares, isto, se dá principalmente as condições sócio econômicas de nosso país, pois vivemos em sociedade onde nem todas as pessoas têm oportunidades educacionais iguais.

De acordo com LEVIN (1984), o rendimento escolar vai muito além das fronteiras da instituição escolar. Este rendimento decorre do ambiente familiar, dos recursos investidos pela família, do convívio social, do acesso a informação, pois, quando os pais tem um nível de escolaridade maior, eles tem mais conhecimento, automaticamente mais condições de acompanhar os filhos em suas tarefas escolares. Neste sentido é que:

\begin{abstract}
As autoridades nacionais e locais responsáveis pela educação têm a obrigação prioritária de proporcionar educação básica a todos, mas não se pode esperar delas que proporcionem a totalidade dos elementos humanos, financeiros e organizacionais necessários para essa tarefa. Será necessária a harmonização de ações entre todos os subsetores e todas as formas de educação (...) a harmonização de ações entre o Ministério da Educação e outros ministérios (...) a cooperação entre organizações governamentais e não governamentais, $o$ setor privado, as comunidades locais, os meios de comunicação, os grupos religiosos e a família (...).” (Declaração Mundial sobre Educação para Todos, Jomtien. UNESCO, 2002:125).
\end{abstract}

O que se percebe na educação são prioridades que são substituídas por outros interesses. No entanto os esforços são a nível mundial tem buscado atenuar a diferença entre o que têm e os que não têm. É preciso reconhecer que o país avançou significativamente na assistência aos necessitados, todavia é preciso mais investimento no que é base da desigualdade social.

Todos os segmentos da sociedade precisam estar envolvidos na transformação cultural de um povo. As políticas públicas precisam assistir a grupos e entidades que luta contra esta segregação social que se perpetua por todas as nações.

No entanto, uma das mais relevantes contribuições que os tempos modernos trouxeram para as políticas educacionais foi à concepção de que a escola deveria ser um direito - ou mesmo obrigação - de todos, fossem ou não membros das elites. Foi COMÊNIO (1592 - 1670), bispo tcheco, o primeiro a desenvolver um pensamento educacional que podemos tratar como verdadeiramente moderno. Propôs um sistema articulado de ensino, reconhecendo o igual direito de todos os homens ao conhecimento, desenvolvido através de uma educação permanente, durante toda a vida humana. 
Id on Line Revista Multidisciplinar e de Psicoloqia

Id on Line Multidisciplinary and Psycology Journal

\section{O que ganhamos com a "Educação"?}

A importância de uma educação de qualidade, que oferece meios para o exercício pleno da cidadania, deveria ser foco de qualquer governo e de qualquer País e não somente interesse de uma classe da sociedade, Segundo Reali (1999), os países de primeiro mundo vêm investindo grandemente para superar os desafios da educação, os governos da Organização para Cooperação e Desenvolvimento Econômico (OCDE), tem buscado oferecer uma aprendizagem mais avançada para toda população, independente do status social.

Ainda segundo REALI (1999) "pretendem ainda converter a aprendizagem numa atividade que ocorra ao longo da vida, de modo diverso a um modelo que privilegia a sua concentração nos anos da educação básica”. Percebe-se que, quando o país se preocupa com a qualidade da educação, não privilegiando somente algumas classes sociais, automaticamente o rendimento acadêmico dos alunos aumentam, consequentemente com o passar dos anos, o nível sócio- econômico deste país tende a melhorar.

O contexto familiar, a educação dos pais é de suma importância para o impacto acadêmico dos estudantes, como comentamos anteriormente, entendemos que estes estudos ainda deixaram dúvidas e questões em aberto, que podem e devem continuar a investigação. Porém, através deste estudo concluímos que o caminho para melhorar as condições socioeconômicas de um país é através da Educação e que só se melhora a educação, dando oportunidades de igualdade educacional para todas as classes da sociedade.

\section{Políticas Públicas de Inclusão}

\section{Tramas e Desafios para uma educação inclusiva}

Após inúmeras pressões políticas, sociais educativas, atualmente tem-se medidas legislativas que atestam o direito às pessoas com necessidades educativas especiais de frequentarem as instituições de ensino, fato que cresce a cada dia. Conforme a Organização das Nações Unidas para a Educação, a Ciência e a Cultura (UNESCO), o Brasil é o país da América Latina que mais insere alunos com necessidades especiais em escolas regulares, seguido de México e Chile (Boletim da UNESCO, 1998). 
Id on Line Revista Multidisciplinar e de Psicologia

Id on Line Multidisciplinary and Psycology Journal

E assim, examinando a legislação de vários países do mundo, como o artigo 26 da Declaração Universal dos Direitos Humanos (1948), a Convenção dos Direitos da Criança (1989) e as Diretrizes da Primeira Conferência Mundial sobre a Educação, reunida em Jomtien, Tailândia (1990); o Fórum Mundial sobre a Educação, realizado em Dakar, Senegal (2000), o Estatuto da Criança e do Adolescente (Lei 8069/90), dentre outras, é possível evidenciar o que consta sobre a educação, como sendo um direito humano inalienável, que proporciona aos cidadãos o conhecimento necessário para viver com dignidade. Há unanimidade nas questões econômicas, sociais, políticas, culturais e sanitárias de que não haverá desenvolvimento expressivo nestes setores, sem um investimento na educação (BIANCHETTI, 1995).

Investir em educação constitui a primeira etapa indispensável para assegurar os direitos humanos, tais como a postura de aceitação das desigualdades e da diversidade, a redução da pobreza, a aceitação de avanços na saúde e nutrição, o controle de crescimento demográfico, dentre outros.

Ao longo da história, o cenário, particularmente no que se refere às pessoas com necessidades especiais nem sempre foi o de aceitação das desigualdades. Até meados do século XVIII algumas práticas eram executadas com estas pessoas, tais como abandono, afogamentos, asfixia. Ao final do século XVIII e nas três primeiras décadas do século XIX teve início, nos países escandinavos e na América do Norte, o período de institucionalização especializada de pessoas com deficiências, nomenclatura adotada na época.

A partir daí surgiu a Educação Especial. A sociedade tomou consciência da necessidade de atender as pessoas denominadas como deficientes, mas a forma de atendimento priorizava um caráter assistencialista. A assistência era prestada em Centros Especializados, nos quais as pessoas recebiam atendimento de vários profissionais: médicos, psicólogos, psicopedagogos, assistentes sociais.

No século XX, a desinstitucionalização começa a ocorrer com programas escolares para deficientes mentais. Os serviços especiais foram diversificados e as classes especiais passaram a integrar o contexto escolar. No Brasil, as classes especiais foram criadas entre 1960 e 1965 , em todo o país, para pessoas excepcionais. Este era o termo empregado exclusivamente para as pessoas que frequentavam as classes especiais. Estas classes especiais contribuíram novamente para a segregação e exclusão. 
Id on Line Revista Multidisciplinar e de Psicologia

Id on Line Multidisciplinary and Psycology Journal

A partir de 1980, esta terminologia deficiente foi alterada para pessoas portadoras de deficiência. A partir de 1986 houve a substituição de pessoas portadoras de deficiência, bem como de excepcionais, específica das classes especiais, para pessoas com necessidades educativas especiais. Mas, a adoção desta terminologia foi um processo lento. Ainda hoje em dia é possível ouvir referências aos deficientes, aos excepcionais, apesar da existência legal das nomenclaturas oficiais. Tal questão pode ser atribuída à lentidão na aceitação real da educação inclusiva e nas resistências às mudanças no cotidiano da educação (CARDOSO, 2003).

Ainda, no ano de 1986 surgiu também a proposta de integração educativa,que representou um avanço significativo. O ensino dos alunos com necessidades educativas especiais poderia ser realizado no contexto da escola regular

No Brasil, mudanças começaram a ocorrer na nomenclatura: de alunos excepcionais alterou-se para alunos com necessidades educativas especiais, o que ocorreu em 1986, pela Portaria CENESP/MEC, n.69, ainda que efetivamente não houvesse um avanço expressivo na inserção desses alunos no ensino regular. A Constituição Brasileira de 1988 também trata deste assunto.

No capítulo III, da Educação, da Cultura e do Desporto, artigo 205, prescreve que "a educação é direito de todos e dever do Estado e da Família.” Em seu artigo 208, prevê mais especificamente que "[...] o dever do Estado com a educação será efetivado mediante a garantia de: [...] atendimento educacional especializado, preferencialmente na rede regular de ensino" (BRASIL, 1988).

A Lei de Diretrizes e Bases da Educação Nacional (LDB) mais recente - Lei nº 9.394 de 20/12/1996 - conceitua e orienta a abordagem inclusiva para os sistemas regulares de ensino dando ênfase, no capítulo V, especialmente à Educação Especial. Referencia no artigo 59, que “[...] os sistemas de ensino assegurarão aos educando com necessidades especiais: currículos, métodos, técnicas, recursos educativos e organização específica, para atender às suas necessidades" (BRASIL, 1996).

Anteriormente, no ano de 1994, mais precisamente em 10 de junho, na cidade de Salamanca, na Espanha, ocorreu a Conferência Mundial de Educação, patrocinada pelo governo espanhol e pela UNESCO, com representantes de 92 países e 25 organizações internacionais. Nesta conferência foi reafirmado o compromisso com a educação para todos e elaborada uma declaração, conhecida na história da educação como a Declaração de Salamanca, que apresenta 
metas de ação na sociedade e é considerada um marco na documentação em favor da educação inclusiva.

No entanto, é necessário refletir sobre as implicações da legislação, das políticas públicas de inclusão de alunos que apresentam necessidades educativas especiais. A legislação existe, mas a educação inclusiva baseia-se em fatores mais abrangentes do que somente os legislativos. Uma das questões centrais reside em como tornar compatível essa realidade heterogênea com os esquemas, as tradições e as inércias profissionais de alguns professores, bem como de setores das sociedades que ainda fundamentam suas práticas em modelos que não estão preparados para trabalhar a diversidade e a diferença.

É sabido que a estrutura escolar foi historicamente construída obedecendo a critérios racionalistas, com base no conceito de normalidade, de forma que os alunos aptos a superar os obstáculos de apreensão dos conteúdos tivessem acesso aos níveis mais elevados de ensino. Nessa ordem, aqueles com ritmo mais lento ou diferenciado de aprendizagem, deveriam seguir por outros caminhos, segregados ou ignorados pelo sistema escolar.

Nessa perspectiva, a predominância de conteúdos eruditos e científicos vem reforçando a primazia da razão e do fazer técnico, em detrimento dos aspectos subjetivos e criativos das experiências dos alunos. Esse fato estabelece a manutenção de uma hierarquia de saberes que valorizam os alunos com ritmo acelerado de apreensão de conceitos científicos, favorecidos por seu meio social, cultural e econômico, reproduzindo e mantendo essa ordem.

Inserem propostas de ensino, de vivências culturais a partir da perspectiva de homogeneização, ou então, mantém a segregação e $\mathrm{o}$ isolamento de pessoas com necessidades educativas especiais, sem uma leitura crítica da realidade. Tal estrutura visa beneficiar mais alguns segmentos da sociedade mantendo a maioria das pessoas com necessidades educativas especiais afastada do processo de interação escolar e social, bem do acesso aos meios e instituições de produção e de veiculação cultural.

Concebe-se que na visão da escola inclusiva impõe a demolição dos discursos educacionais que excluem as diferenças, pois:

A fronteira que separa de forma nítida aqueles olhares que continuam pensando que o problema da educação escolar está na anormalidade, no anormal, bem como daqueles que pensam o oposto: os que consideram anormalidade, a norma, o normal como o problema em questão é que deveria ser colocado sobsuspeita. Trata-se de representações 
que se apresentam como científicas e acadêmicas, vigiando cada desvio, descrevendo cada detalhe das patologias, cada vestígio da normalidade, suspeitando de toda deficiência com a conhecida afirmação de que "algo está errado no sujeito, que possuir uma deficiência é um problema”(SKLIAR, 2003, p.18).

No Brasil, com base na legislação, o ensino inclusivo despontou como realidade, trazendo em seu bojo tanto a aceitação das diferenças, quanto questionamentos sobre a capacitação dos professores, sobre os modelos de aprendizagem vigentes nas escolas, sobre a adequação das escolas, como também, sobre as responsabilidades das famílias e da sociedade nesse processo.

As pesquisas do sociólogo e crítico Pierre Bourdieu (2004) Demonstraram que a escola não consegue corrigir as desigualdades sociais. Ao contrário, ela acaba contribuindo para que essas desigualdades se repitam quando privilegia os herdeiros, ou seja, aqueles que a socialização familiar já preparou para o ensino (BOURDIEU, 1970).

O processo de superação desse modelo implica em se desestabilizar os parâmetros até então tidos como formadores desse habitus e apontar para outro horizonte, no qual as capacidades de desenvolvimento possam ser ampliadas a partir de novas percepções do sujeito escolar. O movimento impulsionado pela Declaração Mundial de Educação para todos (1990) tem desencadeado mudanças legais e novas abordagens pedagógicas, que contemplam a inclusão em educação e a construção de novas estratégias pedagógicas que possam refletir a diversidade.

Trata-se de um processo mais amplo, que requer mudança de paradigmas, movimento, busca de aproximações com linguagens contemporâneas, com novos domínios, novas mídias; transformações nas práticas e de ensino, com reconhecimento de representações culturais. Implica em não perder de vista o caráter provisório do conhecimento, suas possibilidades emancipatórias e democratizantes, que incluem considerações sobre distintos contextos sociais. A interlocução é a chave para abrir portas na subjetividade conformista, ao insistir que os homens são essencialmente sujeitos e comunicação (FREIRE, 1971).

Pois a educação inclusiva compreende a Educação especial dentro da escola regular e transforma a escola em um espaço para todos. Ela favorece a diversidade na medida em que considera que todos os alunos podem ter necessidades especiais em algum momento de sua vida escolar. Há, entretanto, necessidades que interferem de maneira significativa no processo 
Id on Line Revista Multidisciplinar e de Psicologia

Id on Line Multidisciplinary and Psycology Journal

de aprendizagem e que exigem uma atitude educativa específica da escola como, por exemplo, a utilização de recursos e apoio especializados para garantir a aprendizagem de todos os alunos.

A Educação é um direito de todos e deve ser orientada no sentido do pleno desenvolvimento e do fortalecimento da personalidade. $\mathrm{O}$ respeito aos direitos e liberdades humanas, primeiro passo para a construção da cidadania, deve ser incentivado.

Educação inclusiva, portanto, significa educar todas as crianças em um mesmo contexto escolar. A opção por este tipo de Educação não significa negar as dificuldades dos estudantes. Pelo contrário. Com a inclusão, as diferenças não são vistas como problemas, mas como diversidade. É essa variedade, a partir da realidade social, que pode ampliar a visão de mundo e desenvolver oportunidades de convivência a todas as crianças.

Preservar a diversidade apresentada na escola, encontrada na realidade social, representa oportunidade para o atendimento das necessidades educacionais com ênfase nas competências, capacidades e potencialidades do educando.

\section{Considerações Finais}

Percebeu-se através desta pesquisa, um resgate Histórico das políticas públicas educacionais brasileira, que elas foram reformuladas a cada década e a cada mudança de governo, ao longo do tempo.

A pesquisa sinalizou para que os profissionais da educação tenham capacidade de agir na escola e nas universidades, e para isto é preciso oferecer-lhes formas de compreensão das complexas relações que envolvem essas instituições tanto no aspecto teórico e prático. Saber interagir o histórico da educação e as diferentes propostas de políticas educacionais. Ligandoas às sociedades que construíram tendo uma visão mais abrangente sobre as instituições educacionais, visão essa necessária para se compreender a ação político pedagógica.

É preciso pensar as Políticas Públicas no que tange as Políticas Educacionais como sendo um fator de que se precisa reverter investimentos para combater a exclusão social.

A exclusão social precisa ser analisada e pensada por todos os atores que envolvem a vida da nação. Não ter práticas que visam retirar os excluídos é carregar estigma de que uns 
podem se alimentar, comer, vestir e ter lazer, enquanto as outras pessoas isto é vedado. Vale ressalta que:

O processo de desenvolvimento dos seres humanos segue a aprendizagem, mas
vai além dela, ativando potenciais humanos. "A aprendizagem e o
desenvolvimento, ainda que diretamente ligados não se processam
simetricamente. O desenvolvimento não é estanque, nem acompanha a
aprendizagem como uma sombra acompanha o objeto que a projeta"
(VYGOTSKY, 1984, p.79).

Existe uma dependência recíproca, complexa e dinâmica, que não pode ser explicada por uma única fórmula especulativa, nem apriorística.

Para Vygotsky (1984; 1987; 2003) a interação social é fundamental no desenvolvimento humano e na aprendizagem. Com base nessa afirmativa, a avaliação não pode ser definida de modo estanque, a priori, fechada em si mesma. A avaliação está integrada ao currículo e não pode ser dissociada do projeto educativo em sua totalidade, incluindo as políticas públicas, os projetos escolares, as propostas implícitas e a diversidade sócio-educacional.

A abertura das escolas para as diferenças tem a ver, dentre outras questões, com uma mudança radical nos processos de ensino e aprendizagem. Inclui uma proposta de ruptura entre as fronteiras existentes em diferentes disciplinas, entre saber e realidade. Isso implica em uma valorização da multiplicidade, da integração de saberes, das redes de conhecimento que, a partir daí se formam e se constituem e que se inserem também nas novas tecnologias da informação. Assinala para a transversalidade das áreas curriculares e para a autonomia intelectual do aluno, autor do conhecimento e que, por isso mesmo, imprime valor ao que constrói. Esse processo não pode prescindir da interação social.

Em detrimento do estudo, verificou-se, também que a educação inclusiva é uma possibilidade de romper as barreiras que viabilizam a aceitação das diferenças entre as pessoas. Mas, trata-se de um processo complexo, que exige capacitação, exercício da tolerância, conhecimento e que também necessita de avaliação permanente.

Diferentes terminologias percorrem hoje a trajetória rumo à diversidade, o que se presencia na educação inclusiva. Implica, no entanto, que cada país deve definir e adotar políticas públicas pensadas desde sua própria realidade, apropriadas ao contexto, à sociedade e à cultura, e o processo de avaliação não pode ser dissociado desses princípios norteadores. 
Id on Line Revista Multidisciplinar e de Psicologia

Id on Line Multidisciplinary and Psycology Journal

Portanto, a educação inclusiva de qualidade, que vise realmente integrar diferenças deve convocar os governantes, os professores, as famílias e a sociedade como parceiros diante desses desafios. Mais do que isso: trata-se da necessidade de rever paradigmas, de analisar a legislação, de conhecer e contextualizar políticas públicas contemporâneas.

Não há um modelo único para ensinar, assim como nem todos os seres humanos apresentam ritmos idênticos para aprender. Ainda, há aprendizagens distintas, assim como cada ser humano é diferente do outro. Uma visão hegemônica de ensino, na qual todas as crianças aprendem do mesmo modo e no mesmo ritmo é uma utopia, um contido expansivo, que não pode ser aprisionado por nenhuma ideologia, nenhuma legislação.

A multiplicidade representa o convite para a coragem de espiar por frestas inusitadas e conseguir ver outras dimensões da realidade. Trata-se de uma subversão do olhar. Morin (2000) descreve que as interações entre indivíduos produzem a sociedade que, por sua vez, testemunha o surgimento da cultura, e que retroage sobre os indivíduos pela cultura.

Assinala que a complexidade não poderia ser compreendida dissociada dos, "elementos que constituem: todo o desenvolvimento verdadeiramente humano significa o desenvolvimento conjunto das autonomias individuais, das participações comunitárias e do sentimento de pertencer à espécie humana" (MORIN, 2000, p.52).

Para as escolas, essas afirmativas devem conduzir ao reconhecimento e à legitimação de novas práticas, reconhecendo e respondendo às necessidades diversificadas dos alunos, acomodando os diferentes estilos e ritmos de aprendizagem, assegurando uma educação de qualidade para todos.

Assim, o estudo propôs uma reflexão acerca das políticas públicas quanto à educação inclusiva, como também, pensar a diferença como uma marca humana, presente em todas as situações sociais e, consequentemente, em todas as salas de aula, nos diversos níveis e modalidades de ensino e realidades sócio-culturais.

\section{Referências}

ALENCAR, Eunice M. L. Soriano de A Criança na Família e na Sociedade. Petrópolis, Vozes, 1985. 
Id on Line Revista Multidisciplinar e de Psicologia

Id on Line Multidisciplinary and Psycology Journal

AZEVEdo, Janete M. Lins de. A Educação como Política Pública. Campinas-SP: Autores Associados, 2004.

BIANCHETTI, L. Aspectos Históricos da Educação Especial. Revista Brasileira de Educação Especial, Piracicaba, v.II, n.3, p.7-19, 1995.

BORDIEU, P. A Economia das Trocas Simbólicas. São Paulo :Perspectiva, 2004 .

BRASIL, Constituição (1967). Constituição da Republica Federativa do Brasil -14 de Janeiro de 1967. Brasília, DF: Fundação Projeto Rondon - Minter, 1986.

BRASIL. Boletim da UNESCO sobre Educação Inclusiva. Brasília: Corde, 1998.

BRASIL. Constituição da Republica Federativa do Brasil. São Paulo: Atlas, 1988

BRASIL. Lei de Diretrizes e Bases da Educação Nacional. Lei n. 9394, de 20 de dezembro de 1996. D.O.U. de dezembro de 1996. Florianópolis: Sindicato das Escolas Particulares de Santa Catarina, 1996.

BRASIL. Ministério da Educação e Cultura. Portaria CENESP/MEC, n. 69. Brasília, 1986.

BRASIL. Ministério da Educação e do Desporto. Lei de Diretrizes e Base. Lei no 9394/96.Carta Capital. Revista Periódica. Abril de 2004.

CARDOSO, M. Aspectos Históricos da Educação Especial: Da Exclusão a Inclusão - Uma Longa Caminhada. IN: MOSQUERA, J. M. e STOBAUS, C. (Org.) Educação Especial: Em Direção a Educação Inclusiva. Porto Alegre: EDIPUCRS, 2003,P.15/26.

CARNOY, Martin. Mundialização e Reforma na Educação. Brasília, UNESCO, 2002.

CASASSUS, Juan. A Escola e a Desigualdade. Brasília, Plano, 2002.

CHAUÍ, Marilena. Conformismo e Resistência: Aspecto da Cultura Popular no Brasil. São Paulo, Brasiliense, 1986.

COSTA, Messias. Rendimento Escolar no Brasil e a Experiência de Outros Países. São Paulo, Loyola, 1990.

DECLARACAO DE SALAMANCA E LINHA DE ACAO SOBRE NECESSIDADES EDUCATIVAS ESPECIAIS. Brasília: Corde, 1994.

DINIZ, D. e GUILHELM, D. O que é Deficiência. São Paulo: Brasiliense, 2007. 
DOROTEU, Leandro Rodrigues. Políticas públicas pelo direito à educação no Brasil. In: Âmbito Jurídico, Rio Grande, XV, n. 104, set 2012. Disponível em: <http://www.ambitojuridico.com.br/site/?n_link=revista_artigos_leitura\&artigo_id=12209>. Acesso em jun 2016.

DURU-BELLAT, M. Vencer o Grande Desafio da Igualdade de Oportunidades. Label France: Revista do Ministério de Relações Exteriores. n.54,Abril-Junho 2004.

FREIRE, P. Educação como Pratica e Liberdade. Rio de Janeiro: Paz e Terra, 1971.

FREIRE, P. Pedagogia da Autonomia: Saberes Necessários a Pratica Pedagógica. Rio de Janeiro: Paz e Terra, 1977.

GOMES, Alberto Cândido. A Educação em Perspectiva Sociológica. $3^{\text {a }}$ ed. São Paulo, EPU, 1994.

GUTIERREZ, F. Linguagem Total: Uma Pedagogia dos Meios de Comunicação. São Paulo: Summus, 1978.

http://novaescola.org.br/formacao/palavra-especialista-desafios-educacao-inclusiva-focoredes-apoio-734436.shtml

INEP/MEC. Enciclopédia de pedagogia universitária: glossário vol. 2 / Editora-chefe: Marília Costa Morosoni. - Brasília: Instituto Nacional de Estudos e Pesquisas Educacionais Anísio Teixeira, 2006.http://www.mec.gov.brhttp://www.infoescola.com/educacao/politicaeducacional/

LA TAILLE, Y. Piagey, Vygostky e Wallon :Abordagens Psicogenéticas em Discussão. São Paulo: Summus, 1996.

LARrosA, J. e SKLiAR, C. (Org). Habitantes de Babel. Política e Poética da Diferença. Belo Horizonte: Atlântica, 2002.

MANTOAN, M. T. O direito de ser, sendo diferente na escola. IN: RODRIGUES, D. (Org). Inclusão e Educação: Doze olhares sobre a Educação INCLUSIVA. São Paulo: Companhia das Letras, 2001. p.133-209.

MCLAREN, P. A Vida nas Escolas: Uma Introdução a Pedagogia Critica nos Estados Unidos. Porto Alegre: ARTMED, 1997.

MORIN, E. Os Sete Saberes Necessários a Educação do Futuro. São Paulo: Cortez, 2000.

OLIVEIRA, M. K. Vygotsky: Aprendizado e Desenvolvimento -O Processo Sócio Histórico. São Paulo: Scipione, 2005.

PATTO, M. H. S. O Fracasso Escolar. São Paulo, s. e., 2004. 
Id on Line Revista Multidisciplinar e de Psicologia

Id on Line Multidisciplinary and Psycology Journal

RODRIGUES, D. Educação e Diferença: Valores e Praticas para uma Educação Inclusiva. Portugal: Porto, 2006.

ROMANELLI, Otaíza de Oliveira. História da Educação no Brasil. Petrópolis: Vozes, 2005.

SAVIANI, Dermeval. A Política Educacional no Brasil. In. STEPHANOU, M.; BASTOS, M. H. C. (Orgs). Histórias e Memórias da Educação no Brasil. Petrópolis -RJ: Vozes, 2005.

SHIROMA, Eneida Oto; MORAES, Maria Célia M. de; EVANGELISTA, Olinda. Política Educacional. Rio de Janeiro: DP\&A, 2002, $2^{\text {a }}$ Ed

SILVA, T. T. A Política e a Epistemologia do Corpo Normalizado. Rio de Janeiro: Espaço, 1997.

SKLIAR, C.E se o Outro não estivesse ai? Notas para uma Pedagogia (Improvável) da Diferença. Rio de Janeiro: DP\&A, 2003.

TORRES, Carlos Alberto. Teoria Crítica e Sociológica. São Paulo: Cortez, Instituto Paulo Freire, 2003.

UNESCO. Declaração Mundial de Educação para Todos: Plano de Ação para satisfazer as necessidades básicas do aprendiz. Tailândia, 1990.

UNESCO. Educação na América Latina: Análise de Perspectivas. Brasília: OREALC, 2002. VYGOTSKY, L. S. La Imaginacion y la Arte en la Infância. Espanha: Akal, 2003.

VYGOTSKY, L. S. Psicologia e Pedagogia: Bases do Desenvolvimento e Aprendizagem. São Paulo: Centauro, 2005.

VYGOTSKY, L. S. Psicologia Pedagógica. São Paulo: Martins Fontes, 1984

Como citar este artigo (Formato ABNT):

NOGUEIRA, M.Z.L. Políticas Públicas Educacionais: Desafios da Inclusão no Ensino Regular. Id on Line Revista Multidisciplinar e de Psicologia, Janeiro de 2017, vol.10, n.33, Supl 2. p. 139-148. ISSN: 1981-1179.

Recebido: 21/12/2016

Aceito: $22 / 12 / 2016$ 